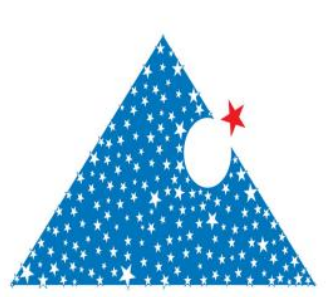

\title{
TIG ve Elektrik Ark Kaynağı ile Birleştirilen Alüminyum Plakaların Mekanik Özelliklerinin İncelenmesi
}

\author{
Riza KARA*, Gökhan YILDIRIM*, Fatih ÇOLAK*, Metehan TINAS* \\ *Uşak Üniversitesi, Teknik Bilimler Meslek Yüksekokulu, Makine ve Metal Teknolojileri Bölümü \\ UŞAK/TÜRKIYE \\ riza.kara@usak.edu.tr
}

\begin{abstract}
Özet: Alüminyum, oksijen ve silisyumdan sonra dünya kabuğunda en yaygın olarak bulunan elementtir. Saf alüminyum nispeten yumuşak ve mukavemet değerleri düşük olup endüstriyel uygulamalarda alaşımlandırılmış halde kullanılır. Alüminyum alaşımları endüstride demir ve alaşımlarından sonra en fazla kullanılan malzemedir. Bu çalışmada Etial-30 kalite Alüminyum levhaların TIG ve Elektrik Ark Kaynak (EAK) yöntemi ile birleştirme kabiliyeti incelenmiştir. Kaynak işlemleri için 100X100X6 mm boyutlarında numuneler kesilmiştir. Kaynak işlemi öncesinde alüminyum plakalar mekanik olarak temizlenmiştir. Temizlenmiş numuneler farklı yöntemler ile kaynaklanmıştır. Hazırlanan numuneler Elektrik Ark kaynă̆ı, ilave telli ve telsiz olarak TIG kaynak yöntemleri ile birleştirilmiştir. Numuneler tek taraftan kaynaklanarak birleştirilmiştir. Kaynakla birleştirilen numunelere çekme deneyi, mikroyapı, mikro sertlik ve SEM analizleri uygulanmıştır.
\end{abstract}

Anahtar Kelimeler: Alüminyum, TIG kaynak yöntemi, elektrik ark kaynağı, mekanik özellikler.

\section{Investigation of Mechanical Properties of Merged Aluminum Plate with TIG and Electric Arc Welding}

\begin{abstract}
Aluminum is the most common element found in the earth's crust after oxygen and silicon. The pure aluminum is relatively soft and tenacity values are low. Therefore, aluminum alloys are used in industrial applications. Aluminum are the most widely used materials after iron and iron alloys. In this study have been investigated weldability with TIG and electric arc welding (EAK) process to the Etial-30 aluminum plate. The samples were cut in sizes of $100 \times 100 \times 6 \mathrm{~mm}$ for welding process. Aluminum plates were cleaned at mechanically before welding process. Cleaned samples were welded by different methods. Prepared samples were combined with electric arc welding and TIG welding process (with additional wire and non-wire). The samples have been combined by welding from one side. The combined samples have been characterized with tensile strength, microstructure, micro hardness and SEM analysis.
\end{abstract}

Keywords: Aluminum, TIG Welding Process, Electric Arc Welding, Mechanical Properties

\section{Giriş}

Günümüzde alüminyum ve alüminyum alaşımları arttırılmış mukavemet özelikleri, hafiflikleri, iyi 1sıl ve elektrik iletkenlikleri, korozyona karşı dirençleri nedeniyle gıda, kimya, otomotiv ve gemi inşa endüstrileri, taşıt, makina ve cihaz yapımı ile mimari alanda, inşaat, havacılık ve uzay

Bu makaleye atıfyapmak için

Kara, R., Yıldırım, G., Çolak, F., Tınas, M., "TIG ve Elektrik Ark Kaynă̆ ile Birleştirilen Alüminyum Plakaların Mekanik Özelliklerinin İncelenmesi”" ElCezerî Fen ve Mühendislik Dergisi 2017, 4(2); 274-281. 
endüstrilerinde geniş kullanım alanına sahiptirler. Bu özellikleri nedeniyle mühendis ve tasarımcılar için tercih edilen endüstriyel malzemeler konumuna gelmişlerdir [1-4]. Alüminyum kullanımının yaklaşık \%25'i taşıt araçlarının üretimine aittir [5]. Alüminyum, standart potansiyeline göre, soy olmayan bir metaldir. Kısa zamanda oksijen ile birleşerek alimün $\left(\mathrm{Al}_{2} \mathrm{O}_{3}\right)$ teşkil eder hava ile temas eden alüminyum yüzeyi üzerinde oluşan sabit bir oksijen tabakası nedeniyle alüminyum alaşımları genellikle atmosfer etkilerine karşı büyük bir mukavemet gösterirler [6]. Atmosferde oluşan bu tabaka ince, renksiz, amorf, su ve su buharı içerisinde daha çok kristalin yapısındadır. Tabaka ne kadar sıkı ve homojen ise, aynı koşullarda korozyon direnci o kadar iyidir. Saf olmayan metallerin ve alaşım yapıcı elementlerin varlığı ile etkilenir [7]. Endüstrinin birçok üretim kolunda alüminyum kaynağı uygulanmaktadır. Bunlara; basınç tankları, yakıt depoları, variller, konteynerler, sıvılaştırılmış gaz bidonları, su tankları vb. örnek olarak verilebilir. Al ve alaşımların kaynağı, az karbonlu çelikler ile karşılaştırıldığında bazı zorluklar göstermesine karşın gerekli önlemler alınarak, uygun bir kaynak bağlantısı elde etme olanağı vardır. Alüminyum ve alaşımlarının kaynaklana bilirliğini sınırlayan hususlar vardır. Alüminyum ve alaşımlarının yüzeyi çok yüksek sıcaklıkta $\left(2050{ }^{\circ} \mathrm{C}\right)$ ergiyen refrakter karakterli bir oksit tabakası ile kaplıdır. Bu oksit tabakası çok sıkı bir şekilde yüzeyi sarar ve oksitlenmenin iç kısımlara doğru ilerlemesini önler. Kaynak sıcaklığında ergimeyen bu oksidin varlığı, kaynak dikişine elektrotun ergimesi ile geçer ve bağlantının sürekliliğini sağlayan damlacıkların bağ oluşturmasına engel olur; bunun yanı sıra kaynak banyosu içinde kalıp katılaşan oksit tabakası, bağlantının dayanımını azaltır [8]. Döküm alaşımlarından bazılarına yaşlandırma sertleşmesi uygulanarak mekanik özellikleri değiştirilir. Bazı alaşımlar ise sadece tavlanarak sünekliği arttırılır [9]. Alüminyum düşük sicaklıkta ergimesi ve ergiyen metalin tav rengi göstermemesi kaynak işlemini güçleştirmektedir; Kaynak bölgesinin kaynak sıcaklığına erişip erişmediği ancak çok deneyimli kaynakçılar tarafindan farkına varılabilmektedir. Alüminyum 1sıl iletkenliğinin yüksek olması, kaynak bölgesinde yerel sıcaklık yoğunlaştırılmasını zorlaştırmakta ve birçok hallerde ön tavı gerekli kılmaktadır. Alüminyumun 1sıl genleşme katsayısının yüksek olması, kaynak bölgesinde şiddetli şekil değişimlerine yol açmakta ve çarpılmaları arttırmaktadır. Yukarıda bahsedilen bu konular alüminyum ve alaşımlarının kaynak olanaklarını sınırlamakta ve kaynak işlemini zorlaştırmakta ise de, gerekli önlemler alınarak uygun bir teknik uygulandığında güvenilir kaynak bağlantıları elde etme olanağı bulunmaktadır [10]. Alüminyum oksit tabakasının kaynak işlemi için olumsuz etkilerinden olan, dikişte oksit kalıntısını azaltmak için kaynak ağızlarına işlem öncesi iyi bir oksit temizleme uygulanması gereklidir [11].

$\mathrm{Bu}$ çalışmada; endüstride geniş yelpazede tercih edilen Etial-30 kalite alüminyum plakaların Elektrik Ark Kaynağı, TIG (İlave Metalsiz) ve TIG (İlave Metalli) yöntemleri ile kaynak kabiliyeti araştırılmıştır. $\mathrm{Bu}$ amaçla farklı kaynak yöntemleri ile yapılan birleştirmelerin mekanik özelliklerinden çekme dayanımı tespit edilerek sertlik dağılımı belirlenmiştir. Ayrıca birleştirmenin metalografik incelemesi yapılarak, mikroyapı mekanik özellik ilişsisi belirlenmiştir.

\section{Deneysel Malzeme ve Metot}

\subsection{Deneysel Çalışmada Kullanılan Malzeme}

Çalışmada kaynak kabiliyetinin yüksek olduğu ve tüm yöntemlerle kaynak edilebildiği tespit edilen Etial-30 alaşımı deney malzemesi olarak seçilmiştir. Deneysel çalışmalarda kullanılan numuneye ait spektro analiz sonucu Tablo 1' de verilmiştir.

Tablo 1. Etial-30 kalite alüminyum plakaya ait spektro analiz sonuçları.

\begin{tabular}{ccccccccc}
\hline Malzeme & $\mathbf{S i}$ & $\mathbf{F e}$ & $\mathbf{C u}$ & $\mathbf{M n}$ & $\mathbf{M g}$ & $\mathbf{C r}$ & $\mathbf{N i}$ & $\mathbf{Z n}$ \\
\hline & 0.105 & 0.463 & 0.0054 & 0.0039 & 0.0022 & 0.00097 & 0.0035 & 0.0127 \\
Etial - 30 & $\mathbf{T i}$ & $\mathbf{B e}$ & $\mathbf{B i}$ & $\mathbf{P b}$ & $\mathbf{S n}$ & $\mathbf{V}$ & $\mathbf{Z r}$ & $\mathbf{A l}$ \\
& 0.019 & 0.00003 & $<0.0003$ & $<0.0019$ & 0.0011 & 0.0065 & 0.0013 & 99.2 \\
\hline
\end{tabular}




\subsection{Deney Numunelerinin Kaynak İçin Hazırlanması ve Birleştirilmesi}

Çalışmada Etial-30 alaşımı lamalar 100X100X6 mm boyutlarında giyotin makas yardımıyla kesilmiştir. Kesilen parçalar aralarında kaynak boşluğu bırakılarak küt alın kaynağı tatbik edilmek üzere kaynak masasına yerleştirilerek, işkence ile sıkıştırılarak ısıl değişimlerden etkilenmemesi sağlanmaya çalışılmıştır.

Kaynaklanacak parçaların bir kısmı argon gazı atmosferinde TIG kaynağında alternatif akım ile telsiz ve $\mathrm{AlSi}_{5}$ teli ile iki ucundan puntalandıktan sonra kaynaklanmıştır. Kaynak işlemi torc dikeyle $20^{\circ}$ lik bir açı, ilave telli birleştirmede ise ilave tel yatayla $20^{\circ}$ lik bir açı yapacak şekilde tutulmuştur. Kaynak tek taraflı olarak gerçekleştirilmiştir. Elektrik ark kaynağı yapılırken elektrot yatayla $75-80^{\circ}$ 'lik açı yapacak şekilde tutularak kaynak işlemi gerçekleştirilmiştir.

\subsection{Birleştirmelere Uygulanan Mekanik Testler ve Metalografik Incelemeler}

Birleştirmelerin çekme ve akma dayanımlarını belirleyebilmek amacıyla birleştirmelerden standart çekme numuneleri hazırlanmıştır. Çekme deneyi INSTRON 8801 model çekme test cihazında tek eksende, $0,5 \mathrm{~mm} /$ dak çekme hızında ve sabit sıcaklıkta gerçekleştirilmiştir. Deneysel hataları minimize edebilmek amacıyla her bir şart için 3 deney numunesi test edilmiş ve ortalamaları verilmiştir.

Sertlik dağılımının tespiti kaynaklı bağlantının ana malzeme, ısı tesiri altında kalmış bölge (ITAB) ve kaynak metali bölgelerinden alınan 4 ölçümün ortalaması alınarak; klasik metalografik yöntemlerle hazırlanmış numune üzerinde, HMV SHIMADZU marka mikro sertlik cihazıyla Vickers yöntemi ile 100 gr yük uygulanarak gerçekleştirilmiştir.

Metalografik inceleme numuneleri ise kaynak ilerleme yönüne dik olacak konumda klasik metalografi inceleme yöntemindeki sıralama takip edilerek hazırlanmıştır. Zımparalama işlemleri 80-120-240-320-400-600-800-1000-1200 grid'lik zımparalar kullanılmıştır. Daha sonra parlatma aşamasında çuha bezi kullanılmıştır. Parlatılan numuneler keller olarak bilinen (15 ml HNO3, $10 \mathrm{ml}$ $\mathrm{HCl}, 5 \mathrm{ml} \mathrm{HF}, 70 \mathrm{ml} \mathrm{H} 2 \mathrm{O}$ ) asit çözeltisinde dağlanmıştır. Metalografik incelemeler kullanılarak Olympus marka Bx60 Model optik mikroskop ile gerçekleştirilmiştir.

\section{Sonuçlar ve İrdelenmesi}

\subsection{Mekanik Özellik Test Sonuçları}

Standardına göre test edilen numunelerin çekme test sonuçları aşağıda Tablo 2' de gösterilmiştir.

Tablo 2. Çekme deneyi sonuçları

\begin{tabular}{ccccc}
\hline Kaynak Türü & $\begin{array}{c}\text { Kopma } \\
\text { Bölgesi }\end{array}$ & $\begin{array}{c}\text { Akma } \\
\text { Dayanımı } \\
\text { (MPa) }\end{array}$ & $\begin{array}{c}\text { Çekme } \\
\text { Dayanımı } \\
\text { (MPa) }\end{array}$ & $\begin{array}{c}\text { Uzama } \\
(\%)\end{array}$ \\
\hline $\begin{array}{c}\text { Elektrik Ark } \\
\text { TIG }\end{array}$ & $\begin{array}{c}\text { ITAB } \\
\text { Ana }\end{array}$ & 90 & 82.7 & 7.5 \\
$\begin{array}{c}\text { (Ilave Metalsiz) } \\
\text { TIG }\end{array}$ & $\begin{array}{c}\text { Malzeme } \\
\text { Ana }\end{array}$ & 57 & 123.1 & 15 \\
(Illave Metalli) & Malzeme & & 75.4 & 18.5 \\
\hline
\end{tabular}

Tablodaki her bir değer o şart için test edilen üç numunenin ortalamasıdır. Tablo 1'de tablodan en iyi dayanım ilave tel kullanılmadan TIG kaynağı ile yapılan numunede sağlanmıştır. Yüzde uzamanın ise en iyi olarak ilave telle yapılan TIG kaynağında gözlemlenmiştir. Genel olarak 
sonuçlara bakıldığında alüminyum kaynaklarında kaynak bölgelerinin mukavemetinin düşük olduğu belirlenmiştir. Kaynak bölgesinin çekme mukavemetindeki bu düşüş, kaynak ilave metalinin özelliğinden ve kaynak banyosunda sıkışıp kalan gazların gözeneklerden olduğu düşünülmektedir. Birleştirmelerin sertlik dağılımı da araştırılmıştır. Kaynaklı birleştirmelerin sertlik sonuçları aşağıda Tablo 3' de verilmiştir.

Tablo 3. Uygulanan işlem sıcaklıkları ve sertlik sonuçları

\begin{tabular}{cccc}
\hline Kaynak Türüi & \multicolumn{3}{c}{$\begin{array}{c}\text { Bölgelere Göre Sertlik Değerleri } \\
\left(\mathbf{H V}_{\mathbf{1 0 0}}\right)\end{array}$} \\
\cline { 2 - 4 } & Ana Metal & Kaynak Bölgesi & ITAB \\
Elektrik Ark & 44 & 46.2 & 37.2 \\
TIG (İlave Metalsiz) & 44 & 72.8 & 78.4 \\
TIG (İlave Metalli) & 44 & 68.4 & 43.8 \\
\hline
\end{tabular}

Tablo 3' den görüldüğü gibi kaynaklı birleştirmelerin sertlik değerlerinde çok fazla farklılıklar gözlemlenmemiştir. Ölçülen sertlik değerleri incelendiğinde ilave edilen kaynak telinin sadece kaynak bölgesinde etkisi olduğu tespit edilmiştir. Mikrosertlik testi uygulanmış numunelere ait örnek mikroyapı Şekil 1' de gösterilmiştir.

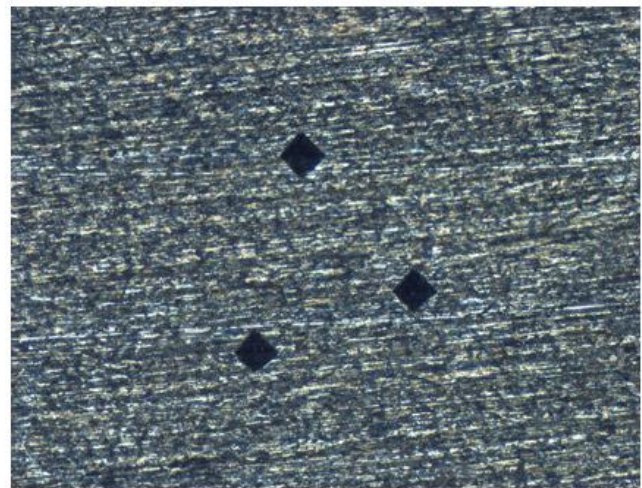

(a)

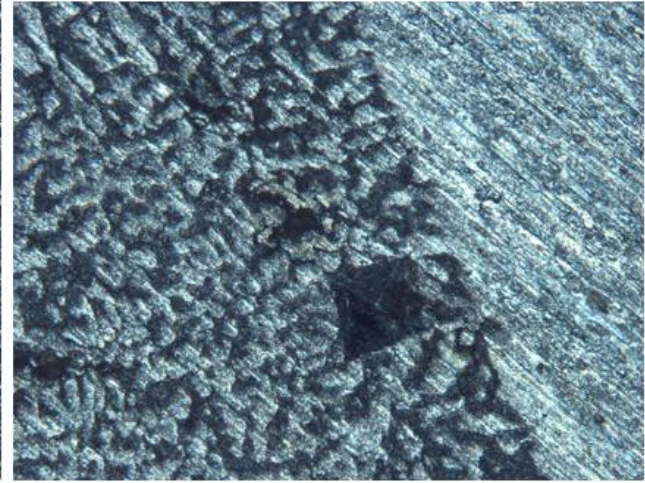

(b)

Şekil 1. Mikrosertlik testine tabi tutulan numune mikroyapısı

a) $100 \mathrm{X}$ b) $200 \mathrm{X}$

\subsection{Metalografik Inceleme Sonuçlart}

Deney malzemesi olarak kullanılan alüminyum plakasının Şekil 2' de kaynaklı parçaların hangi bölgesinden mikroyapı fotoğraflarının alındığı gösterilmiştir. Şekil 3' de alüminyum plakanın kaynak edilmeden önceki içyapı fotoğrafları verilmiştir.

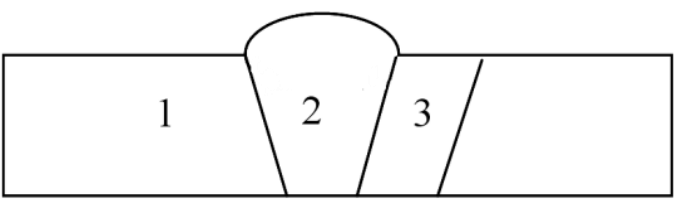

Şekil 2. Mikroyapı fotoğrafı alınan ve kaynak geçiş bölgeleri.

1) Esas Metal, 2) Kaynak Metali, 3) ITAB 


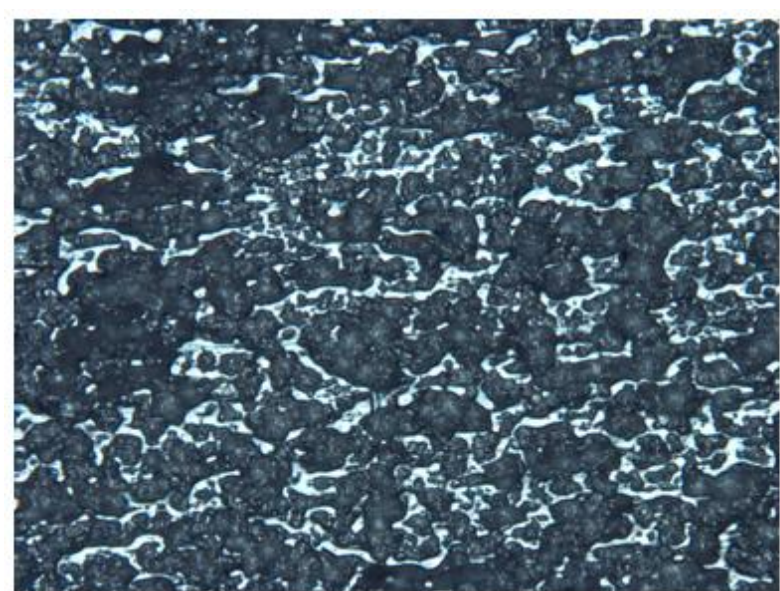

(a)

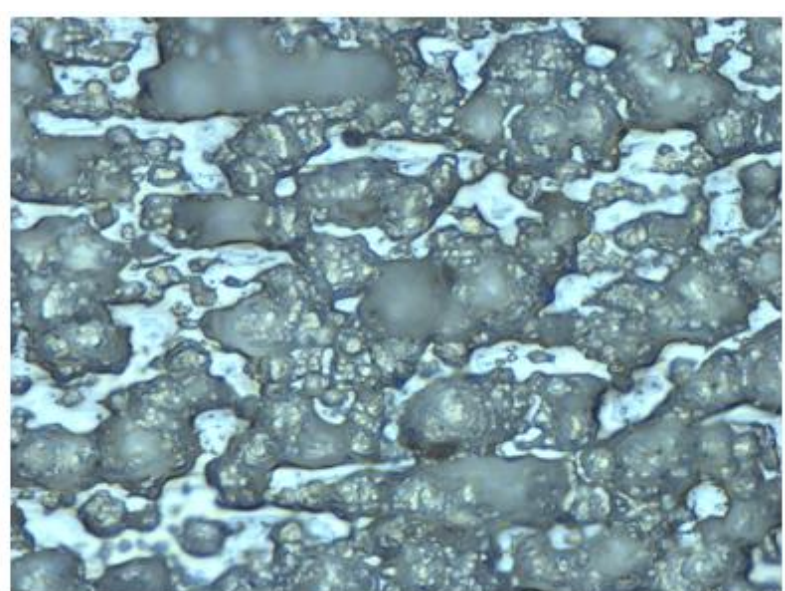

(b)

Şekil 3. Al plakalarının satın alındığı durumdaki mikroyapıları a) $200 \mathrm{X}$ b) $500 \mathrm{X}$

Örtülü elektrot ark kaynağındaki düşük 1sı girdisi veya hızlı soğuma ile taneler kısmen daha ince yapıdadır. Geçiş bölgesinde ise bölgeler arasındaki belirgin tane boyutu farkı gözlenmektedir. Şekil 4' de elektrik ark kaynağı ile birleştirilen numunelerin optik mikroyapıları görülmektedir.

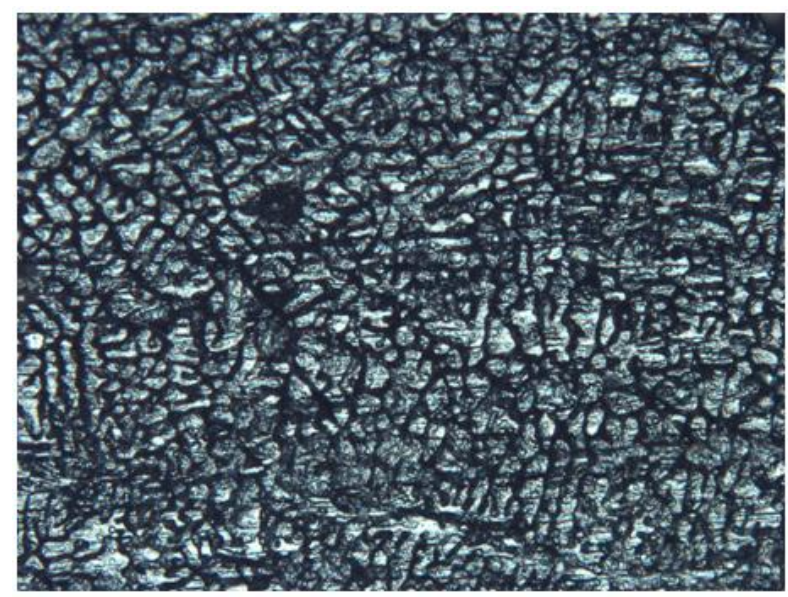

(a)

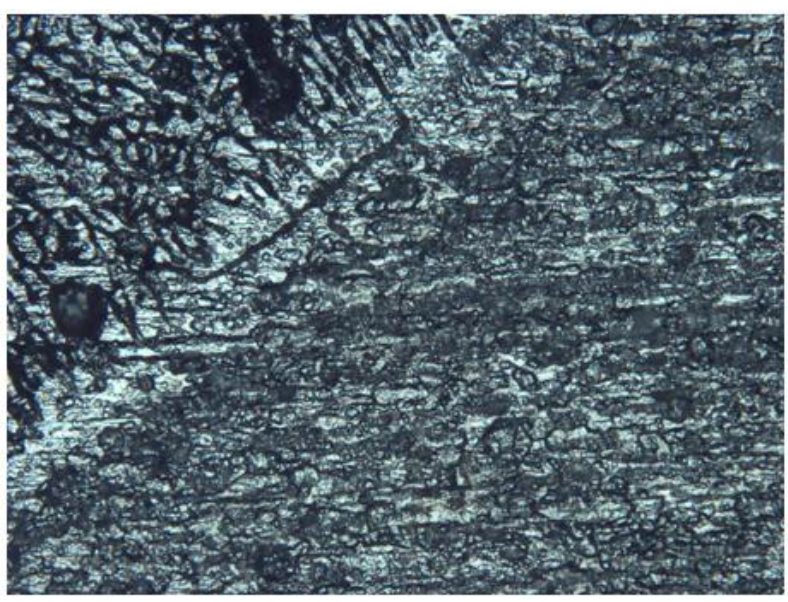

(c)

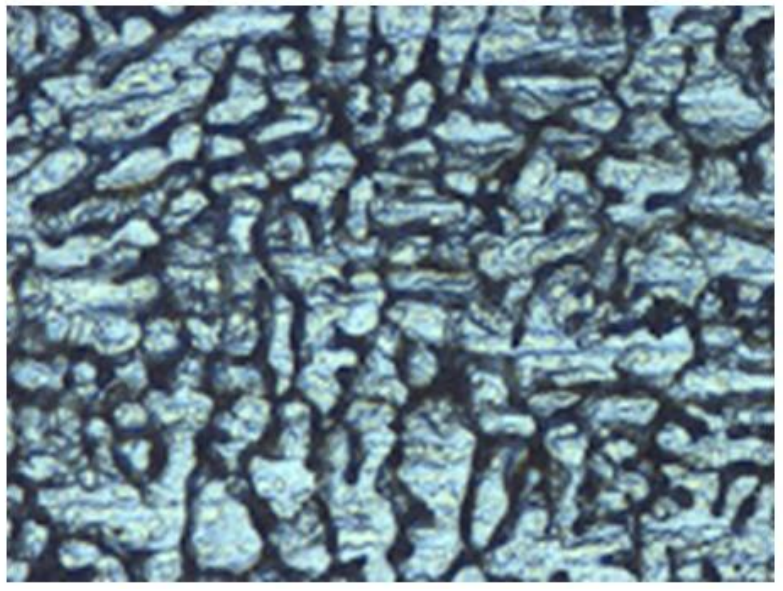

(b)

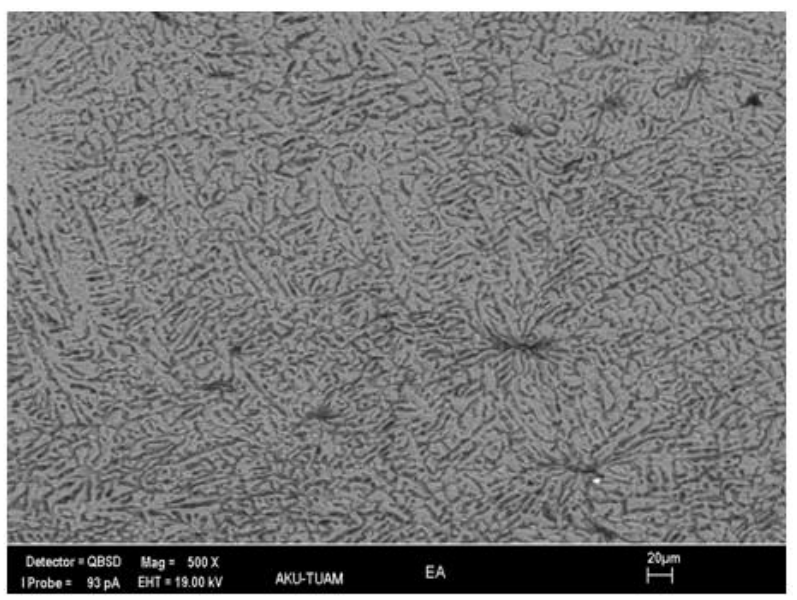

(d)

Şekil 4. Elektrik ark kaynağı ile birleştirilen numunelere ait mikroyapılar a) $200 \mathrm{X}$ b) $500 \mathrm{X}$ c) Geçiş Bölgesi $200 \mathrm{X}$ d) SEM mikroyapısı 
Şekil 5' de ilave metal kullanarak gerçekleştirilen TIG kaynak numunelerin optik mikroyapıları gösterilmiştir. TIG kaynağı ile yapılan alüminyum kaynaklarından başlangıç tane boyutunun örtülü elektrot ark kaynağındakine göre kontrol edilemediği görülmektedir. Tanelerin aşırı irileşmesi ilave tel kullanılması durumunda tane boyutu farkı belirginleşmiştir. Bu duruma kaynakçının kaynak bölgesine ilave tel verme işlemi ile kaynak ilerleme hızının yavaşlaması gösterilebilir. İlerleme hızının azalması ile kaynaklanan numuneler üzerindeki 1sı birikimi ve geç soğuma tane irileşmesine etkilemiştir. Ayrıca çekme deneyi sonucu açısından da bu durum düşünülebilir.

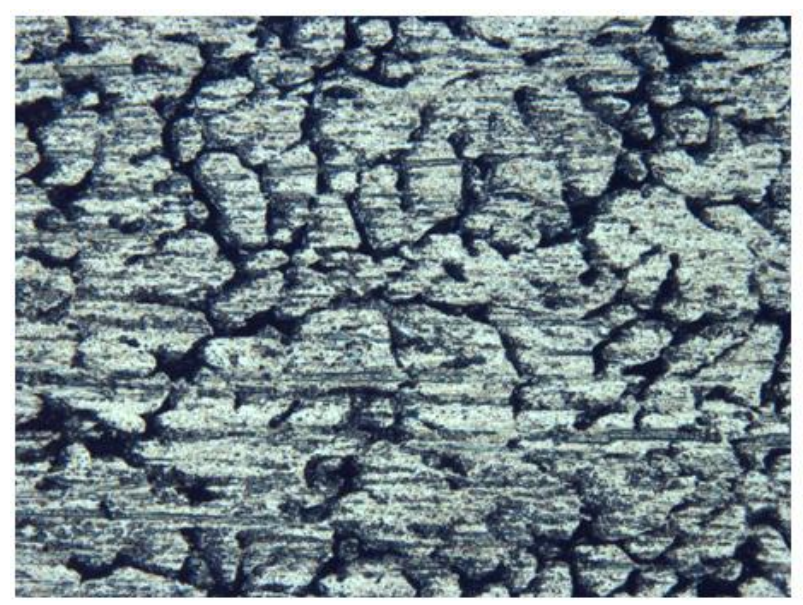

(a)

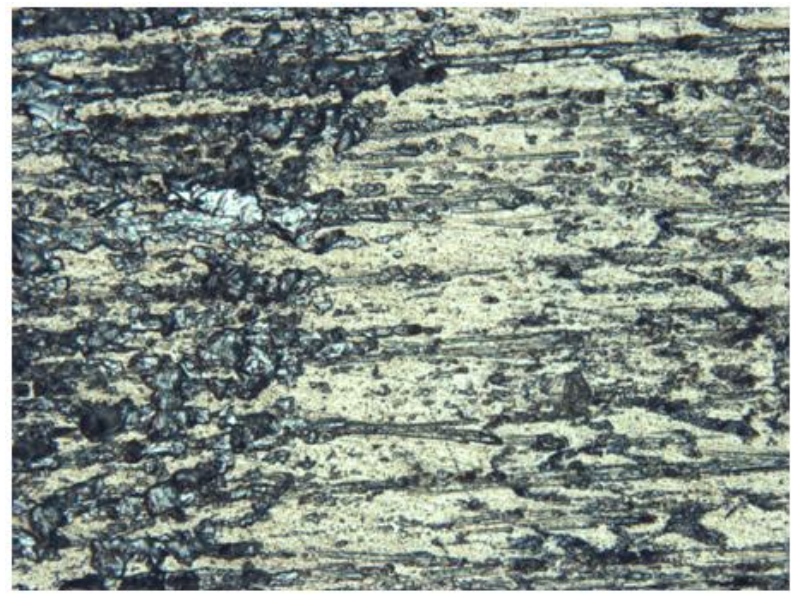

(c)

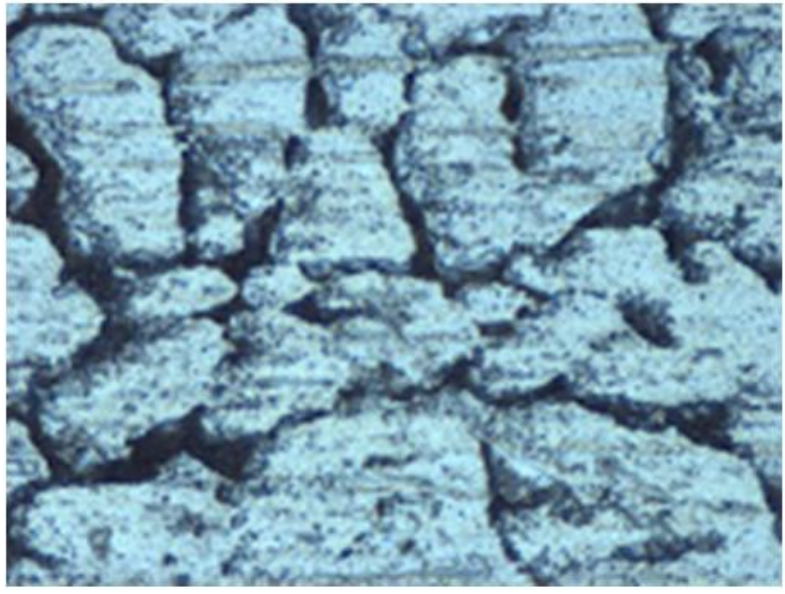

(b)

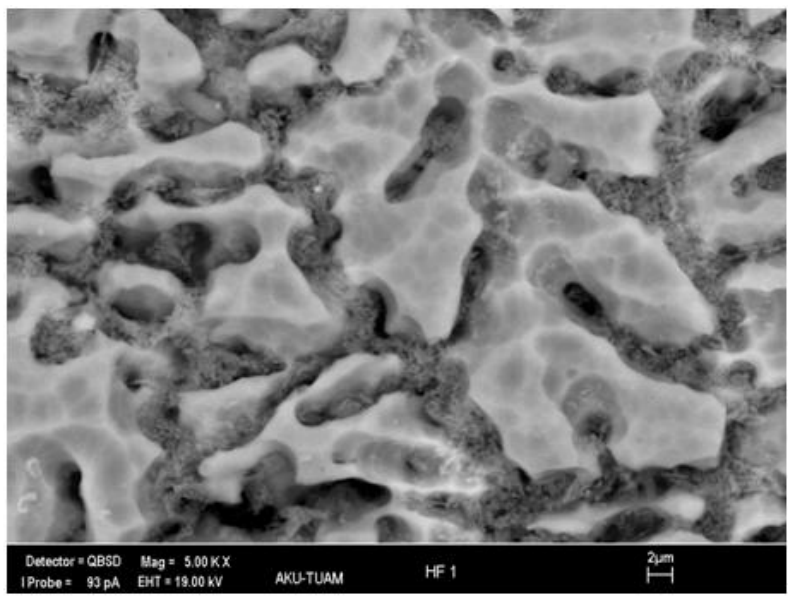

(d)

Şekil 5. TIG kaynağı (İlave Metal) ile kaynaklanmış numunelere ait mikroyapılar. a) 200X b) 500X c) Geçiş Bölgesi 200X d) SEM mikroyapısı.

Şekil 6' da ilave tel kullanılmadan TIG kaynağı ile birleştirilen numunelere ait mikroyapılar gösterilmiştir. İlave metal kullanılmadan birleştirilen numunelerdeki mikroyapı görüntülerinden genel olarak tane boyutunun ilave tel kullanılarak birleştirilen numunelerden daha ince yapıda olduğu görülmektedir. 


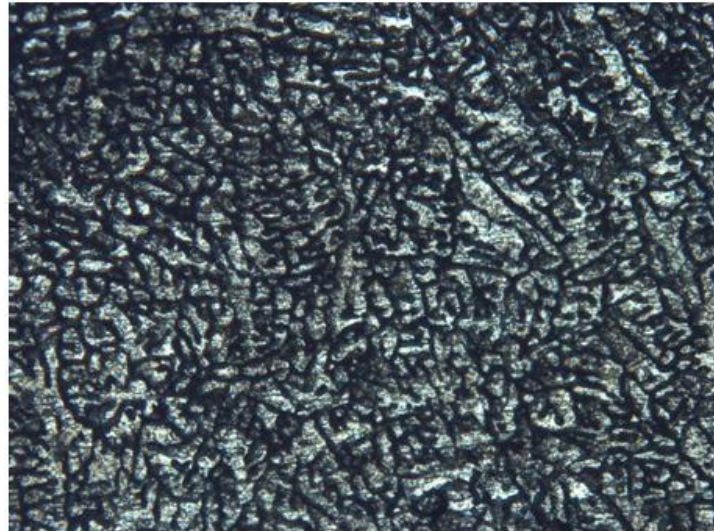

(a)

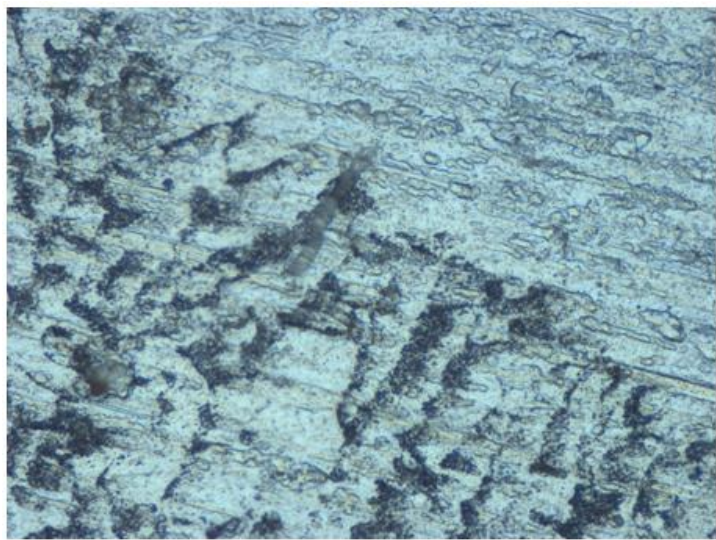

(c)

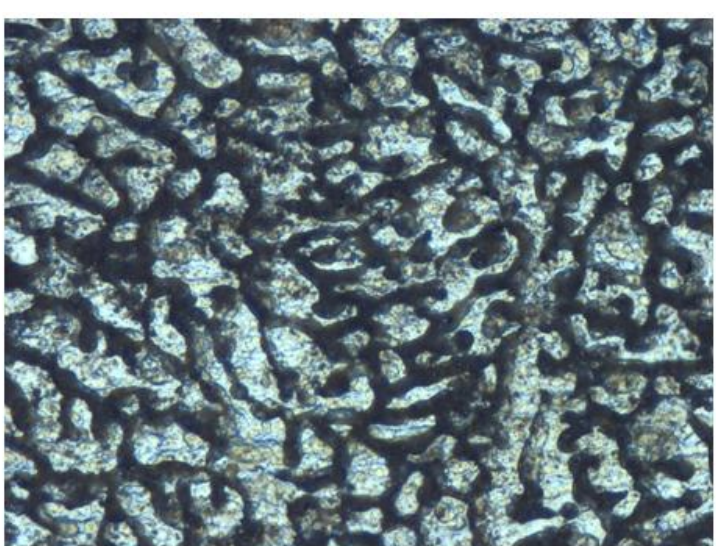

(b)

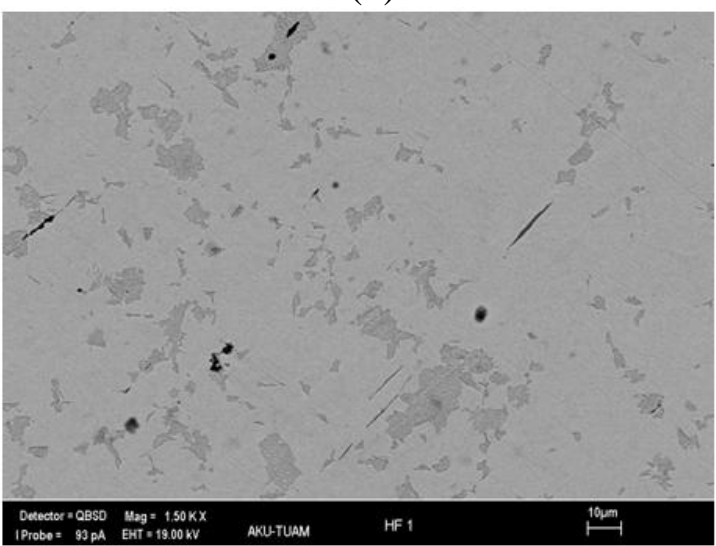

(d)

Şekil 6. TIG kaynağı (İlave Metalsiz) ile kaynaklanmış numunelere ait mikroyapılar.

a) $200 \mathrm{X}$ b) $500 \mathrm{X}$ c) Geçiş Bölgesi 200X d) SEM mikroyapısı

\section{Sonuçlar}

Yürütülen bu çalışmada genel olarak elde edilen bulgularda elektrik ark kaynağı ile birleştirilmiş alüminyum plakalarda 1sı girdisinin TIG kaynağına göre daha düşük olması nedeni ile tane boyutu TIG kaynaklı numunelere göre daha ince olduğu gözlemlenmiştir. TIG kaynağı ile birleştirilen alüminyum plakaların 1sı girdisinin yüksek olması nedeniyle genel olarak tane büyümesi meydana gelmiştir. En yüksek akma gerilmesi ilave metalsiz TIG birleştirmede (90 MPa) ölçülürken, en düşük akma gerilmesi ilave tel kullanılarak TIG kaynak yöntemi ile birleştirilmiş numuneler de (57 $\mathrm{MPa}$ ) elde edilmiştir. Çekme deneyi sonucunda numunelerin kopma bölgeleri dikkate alındığında TIG kaynaklı birleştirmelerde numuneler ana metal bölgesinden kopmuştur. Bu durum TIĞ kaynak yapısında elde edilen dar dikiş ve dar ITAB bölgesi ile açıklanabilir. Ayrıca kaynak işleminin tek taraflı ve tek paso da gerçekleştirilmesi ile TIG kaynağı daha derin nüfuziyet etkisi sağlamıştır.

\section{Kaynaklar}

[1] Anderson, T., "The Advancement of Al within the Welding Fabrication Industry and Its Many Product Design Applications", Svetsaren, (2000), No. 2, pp. 3-5.

[2] Mathers, G., "The Welding of Aluminium and Its Alloys", Woodhead Publishing Limited, Cambridge, UK, (2002).

[3] Welding Handbook, "Welding Processes, Part I", Nintht Edition, AWS, USA, (2004), V. 2. 
[4] Taban, E., Kaluç, E., "En Aw-5083- H321 Alüminyum Alaşımının MIG, TIG Ve Sürtünen Eleman ile Birleştirme (Fsw) Kaynaklı Bağlantılarının Mekanik ve Mikroyapısal Özellikleri”, Mühendis ve Makine, Cilt: 46 Sayı: 541.

[5] Yükler, İ., “Alimunyum Alaşımlar ve Isıl İşlemleri”, İstanbul, (2000).

[6] Tezcan, A., “Alüminyum Alaşımları ve Özellikleri”, Sakarya, (2001), s:1-35.

[7] www.autocad.Virtualave.net/postcard/alkoroz.htm

[8] Karadağ, A., "Alüminyum Alaşımlarının TIG kaynağında kaynak parametrelerinin dikiş geometrisine ve mekanik özelliklere etkisi, Yüksek Lisans Tezi, Sakarya Üniversitesi, (2011).

[9] Brady, G. S., Clauser, H. R., Vaccor, A. J., Hill, M.G., “Alimunyum Alloys”, Materials Handbook, (1989), p. 42-49.

[10] Tülbentçi, K., Kaluç, E., “Alüminyum Alaşımlarının Oksi - Asetilen Kaynağı”, Gedik Teknik, (1995), Sayı : 2 s 3-12.

[11] Gültekin, N., "MIG-TIG Kaynak Tekniği”, Yıldız Üniversitesi Yayınları, Sayı:184, Fatih Gençlik Vakfı Matbaa İşletmesi, (1985 ), s: 104-122. 